\title{
A long-term trend in the F2-layer critical frequency as observed at Alma-Ata ionosonde station
}

\author{
Galina I Gordiyenko*, Victor V Vodyannikov, Artur F Yakovets and Yuriy G Litvinov
}

\begin{abstract}
In this study, we combine monthly median values for the F2-layer critical frequency (foF2), measured at Alma-Ata ionosonde station $\left[43.25^{\circ} \mathrm{N}, 76.92^{\circ} \mathrm{E}\right]$ between 1000 and 1400 (local time), with historical data on the monthly mean values for solar radio flux at $10.7 \mathrm{~cm}$ (F10.7) and the geomagnetic activity index (Ap) (available at http://www.swpc. noaa.gov/), over the period from 1957 to 2012. These data are used to derive long-term trends in the upper ionosphere and to discuss their importance in the context of coupling between solar and geomagnetic activity in the ionosphere at middle latitudes.
\end{abstract}

Keywords: Upper ionosphere; Long-term changes (trends); Solar-ionosphere interactions

\section{Background}

Since Rishbeth (1990) and Rishbeth and Roble (1992) predicted an effect on HF/VHF radio propagation due to the 'greenhouse cooling' associated with lowering of the F2-layer, the long-term variations in the upper atmosphere's and ionosphere's parameters have been the subject of a number of observational and modeling studies (Mikhailov 2006; Lastovicka et al. 2008a; Danilov 2012; and references therein). These studies employed a variety of methods, approaches, and datasets to extract long-term trends in the F2-layer critical frequency ( $f o F 2$ ) and peak height $(h m F 2)$ for the ionospheric F2-layer, and the majority were conducted using ionosonde observations. Table 1 summarizes these studies.

Potential drivers of long-term trends in $f o F 2$ are widely discussed by Yue et al. (2006), Lastovicka (2009), Danilov (2012), and references therein and include long-term variations in solar and geomagnetic activity, increasing concentrations of greenhouse gases (e.g., $\mathrm{CO}_{2}, \mathrm{CH}_{4}$ ) and anthropogenic changes to the ozone layer and the distribution of water vapor. Our study focuses on the role of solar and geomagnetic activity in long-term $f o F 2$ trends, using $f_{0} F 2$ data routinely measured over Kazakhstan at the Alma-Ata ionosonde station $\left[43.25^{\circ} \mathrm{N}, 76.92^{\circ} \mathrm{E}\right]$. Data used in this study cover about five solar cycles between 1957 and 2012. Data measured at the Alma-Ata station

\footnotetext{
* Correspondence: ggordiyenko@mail.ru

Institute of lonosphere, National Center for Space Research and Technology, Almaty 050020, Kazakhstan
}

between 1958 and 1994 have already been used to derive long-term trends, independent of geomagnetic activity (e.g., Danilov 2003). However, this study is the first to use the extended dataset up to the year 2012 to derive long-term trends in $f_{0 F} 2$ (we assume the trend is a longterm linear change in $f o F 2$ over the period between 1957 and 2012).

\section{Methods}

For this study, we used monthly median values of $f_{0} F 2$ averaged over $5 \mathrm{~h}$, between 1000 and 1400 (local time) (Figure 1a). Monthly mean values of the solar radio flux at $10.7 \mathrm{~cm}(F 10.7)$ and geomagnetic activity index $(A p)$ (available at http://www.swpc.noaa.gov/) were also studied as the characteristics of solar and geomagnetic activities can strongly affect the ionosphere (Figure 1b,c). As expected, Figure 1 shows that the temporal variations in all three parameters are dominated by changes in solar activity related to the solar cycle. Assuming a secondorder polynomial dependence on $F 10.7$, foF2' is defined as follows (see the regression line in Figure 2a):

$$
f o F 2^{\prime}=a+b \times(F 10.7)+c \times(F 10.7)^{2}
$$

A higher-order (cubic) regression, as used by Chen et al. (2014), does not provide any significant improvement to the fit: $R^{2}=0.810324$ for a second-order regression versus $R^{2}=0.810385$ for a third-order regression). The regression defined in Equation 1 was then used to remove variations in $f_{o} F 2$ related to the solar activity effect, allowing monthly 
Table 1 List of authors who derived long-term trends in foF2 and their findings

\begin{tabular}{|c|c|c|c|}
\hline Authors & Site: name or number $(N)$ of stations & Years of observation & Trends $\left(\mathrm{MHz}^{-1}\right)$ \\
\hline Danilov (2002) & Sverdlovsk $\left[56.43^{\circ} \mathrm{N}, 58.57^{\circ} \mathrm{E}\right]$ & 1948-1994 & -0.015 \\
\hline Danilov (2003) & $N=21, \varphi>30^{\circ}$ & 1958-mid-nineties & -0.012 \\
\hline Danilov (2013) & $N=12$ & 1990-2010 & -0.024 (1400 local time), -0.054 (after sunset) \\
\hline Mielich and Bremer (2013) & $N=124$ & 1948-2009 & -0.003 to 0.0038 \\
\hline Yue et al. (2006) & $N=19,\left[42.9^{\circ} \mathrm{S}\right.$ to $62.0^{\circ} \mathrm{N}$, ca. $\left.130^{\circ} \mathrm{E}\right]$ & $1948-2005$ & -0.005 \\
\hline Lastovicka et al. (2006, 2008b) & Juliusruh $\left[54.6^{\circ} \mathrm{N}, 13.4^{\circ} \mathrm{E}\right]$ & 1976-1996 & -0.01 to -0.02 \\
\hline Ghabahou et al. (2013) & Ouagadougou $\left[12.4^{\circ} \mathrm{N}, 358.5^{\circ} \mathrm{E}\right]$ & 1966-1998 & -0.015 \\
\hline Khaitov et al. (2012) & Tomsk $\left[56.5^{\circ} \mathrm{N}, 84.9^{\circ} \mathrm{E}\right]$ & $1937-2011$ & -0.008 to -0.014 \\
\hline Mikhailov (2006) & Slough $\left[51.48^{\circ} \mathrm{N},-0.57^{\circ} \mathrm{E}\right]$ & $1935-2000$ & -0.00086 \\
\hline
\end{tabular}

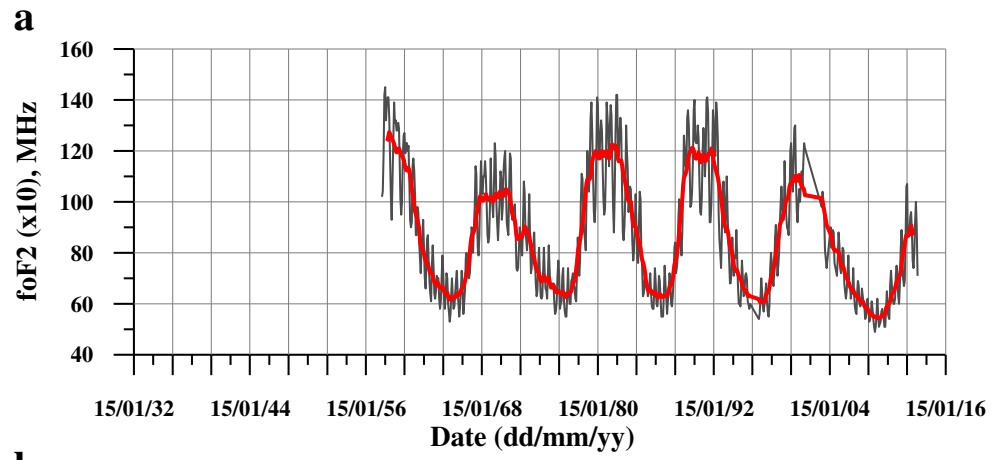

b
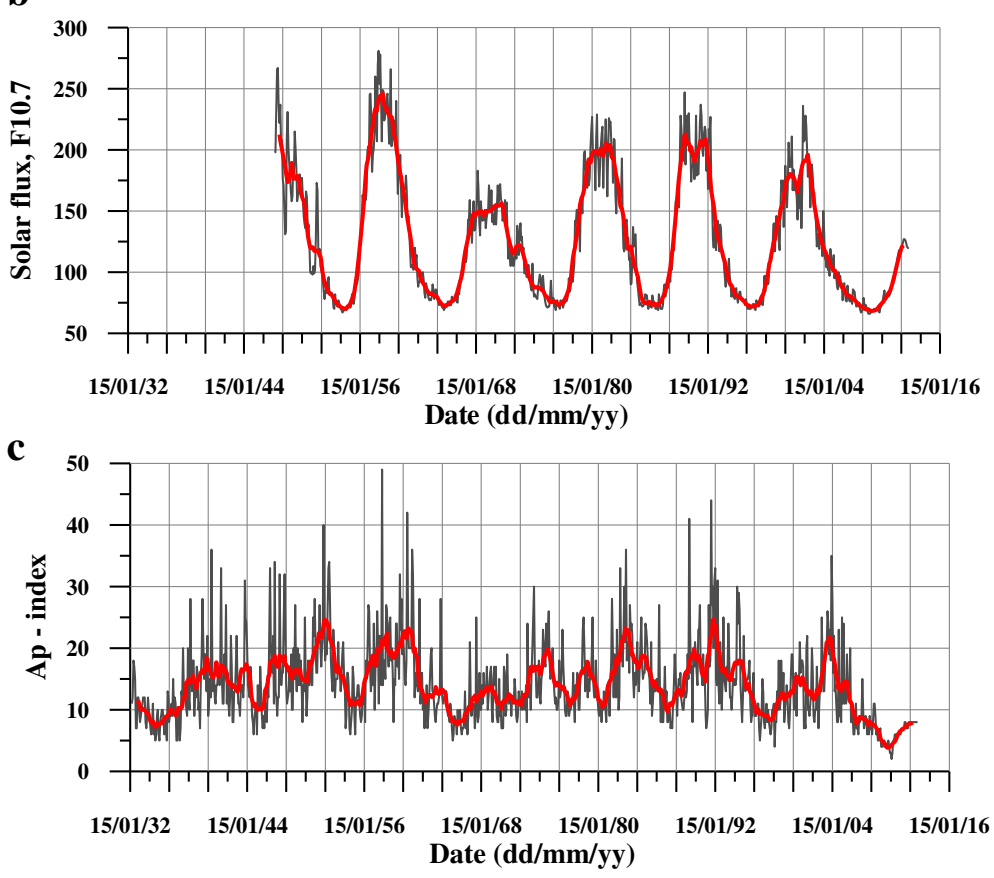

Figure 1 Monthly median near-noon foF2 (a), monthly mean $F 10.7$ (b) and $A p$ (c) values. 




absolute deviations (defined as $\triangle f o F 2=f o F 2-f_{o} F 2^{\prime}$ ), which can potentially reveal long-term trends in $f o F 2$, to be calculated (Figure 2b). However, Figure $2 \mathrm{~b}$ shows that the correlation between $f o F 2$ and $F 10.7$ determined via Equation 1 only accounts for around $80 \%\left(R^{2}=0.810324\right)$, of the variations in $f_{o F} \mathrm{~F}$ and the majority of the $\triangle f o F 2$



variability linked to the 11-year solar cycle. Therefore, to obtain an independent picture of long-term trends in the upper ionosphere, the 11-year (132 months) running mean values of the monthly absolute deviations $\left(\Delta f o F 2_{132}\right)$ were calculated over the entire dataset according to the method set out by Mikhailov (2006). This 11-year smoothing technique was also applied to the F10.7 and Ap datasets but reduced the available period for study to between 1962 and 2006.

\section{Results and discussion}

Figure 3 presents the calculated values for $\triangle f o F 2_{132}$, $F 10.7_{132}$, and $A p_{132}$. Figure 3 shows a pronounced similarity in the $\Delta f o F 2_{132}, F 10.7_{132}$, and $A p_{132}$ variations, which display negative correlations with time and a repeating pattern with a period of ca. 30-32 years. This implies that geomagnetic activity and the Earth's ionosphere are strongly controlled by solar activity. However, it should be noted that the negative trend in geomagnetic activity found here contradicts the generally accepted increase in geomagnetic activity observed throughout the twentieth century (e.g., Clilverd et al. 1998). However, in detail, the geomagnetic activity increased throughout the first half of the twentieth century (along with solar activity) then stabilized (with some increase in $A p$ seen at the end of the 1950s), and then decreased until the beginning of the twenty-first century (with another smaller $A p$ peak observed in the 1980s) (Figures 3 and 4). This study spans the interval from 1957 to 2012, and our data match the overall decrease in $A p$ observed over these years. The trend with a period of ca. 30-32 years is likely to have a solar origin, as it matches a period of 31.1 years that has been found elsewhere in sunspot number spectral analyses (Echer et al. 2004; Clúa de Gonzalez et al. 1993). It has also been suggested that this period of 31 years is the origin of the 35-year Brückner climatic periodicity (Raspopov et al. 2000). Figure 3 shows evidence of the same solar periodicity in $f o F 2$ long-term variations. The Fisher $(\mathrm{F})$ parameter for $f o F 2$ data confirmed that the clear negative trend (ca. $-0.0038 \mathrm{MHz} \mathrm{y}^{-1}$ ) was significant with a confidence level of 95\%-99\%.

Using a similar method to that described for $f_{0} F 2$ above, we calculated the dependence of monthly mean $A p$ on F10.7, allowing the variations in $A p$ related to the solar cycle to be clearly seen (Figure 5 ). Assuming a linear dependence, we defined $(A p)^{\prime}$ as a function of F10.7 and obtained absolute deviations $(\triangle A p)$ as follows:

$$
\begin{aligned}
& (A p)^{\prime}=a+b \times F 10.7 \\
& \Delta A p=A p-(A p)^{\prime}
\end{aligned}
$$

Figure 5 displays the observed $A p$ values (black crosses) versus $F 10.7$, together with the linear regression 


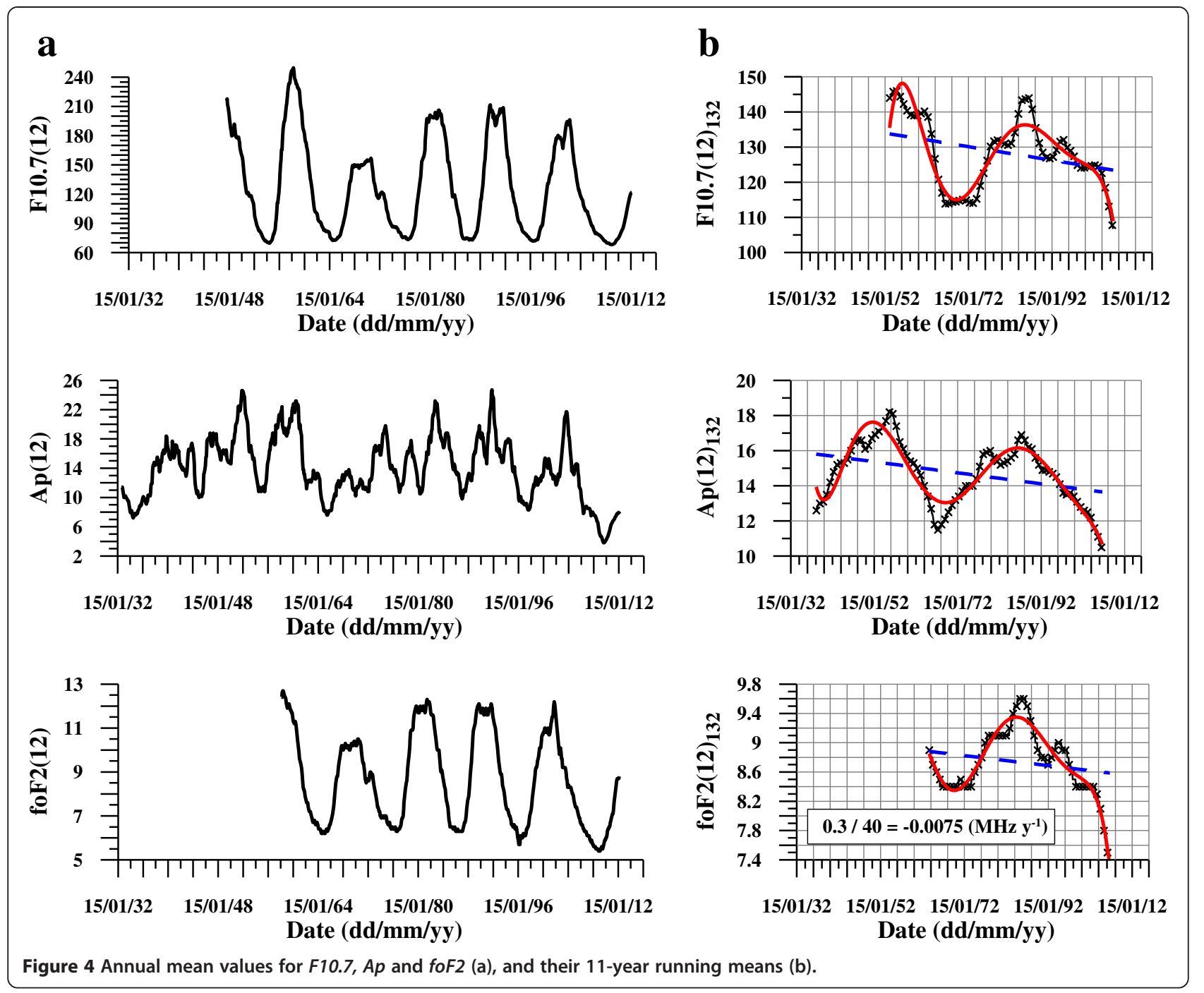

line (solid line), the variations in $A p$ related to solar forcing, and the variations in $\triangle A p$ with time. Approximately $16 \%$ of the variations in the geomagnetic field can be explained by the linear relationship between geomagnetic and solar activities $\left(R^{2}=0.15798\right.$, Figure 5a) and the majority variations in $\triangle A p$ are linked to the 11-year solar circle. Peaks in $\triangle A p$ are slightly shifted (by about 2 to 3 years) relative to the falling phase of the 11-year solar cycle (Figure 5c). Taking this shift into account for the regression calculation did not result in a significantly better fit $\left(R^{2}=0.1698\right)$. These results show that the geomagnetic activity (described by $A p$ ) is strongly linked to the solar cycle phase (solar activity is described by F10.7) and in this study, we were unable to exclude variations in $f o F 2$ related to geomagnetic activity. Analyzing geomagnetic data observed at Kakioka (Japan) and Gnangara (Australia) over almost five solar cycles, Yamazaki and Yumoto (2012) recently found that solar activity controls not only the stationary component of the geomagnetic solar quiet daily variation field $\left(S_{q}\right)$ but also the annual and semi-annual components. They report that all three components have a positive linear correlation with sunspot numbers. Thus, the positive linear correlation between $A p$ and F10.7 found in this study confirms Yamazaki and Yumoto's findings and shows the existence of a long-term coupling between solar and geomagnetic activity that could be used to further our understanding of solar-terrestrial relations.

Our results also show that $f o F 2$ strongly depends on solar activity and shows a negative temporal trend between 1957 and 2012 (about $-0.0038 \mathrm{MHz} \mathrm{y}^{-1}$ ), although the magnitude of this trend is probably too small value to be of practical use. However, it should be noted that the sign of the deduced trend can be dependent on choice of time period for trend analysis. Periods of increasing solar activity (1970-1984) are seen to correspond to positive trends in $f \circ F 2$ and periods of decreasing solar activity (1956-1968, 1986-2004) to 


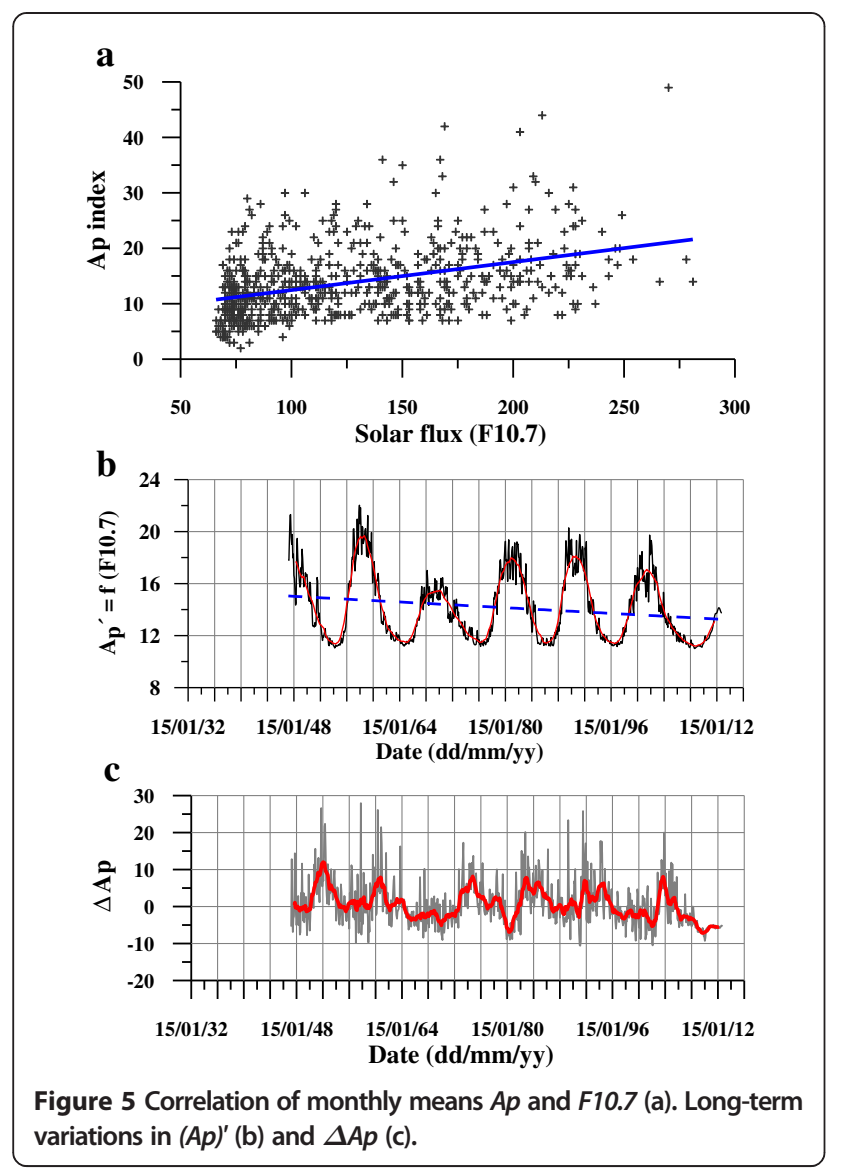

negative trends in foF2 (Figure 3). Therefore, periods of several solar-cycle observations should be used to obtain reliable trend estimates from the data series.

In addition to the material presented above, we derived a picture of long-term changes in the upper ionosphere using annual mean values for $A p$ and F10.7 ( $A p$ (12) and $F 10.7(12))$ and annual median values for $f o F 2$ (foF2(12)). Following a similar method to that described above, Figure 4a,b shows the variations in the 11-year running means $f_{0} F 2(12)_{132}, F 10.7(12)_{132}$, and $A p(12)_{132}$ for the analyzed period. Figure $4 \mathrm{~b}$ shows that long-term trends are similar to those seen in Figure 3, which supports our conclusion that variations in $A p$ and $f_{o} F 2$ are dominantly affected by solar cycles as represented by F10.7. One exception to this conclusion is the somewhat higher foF2 trend $\left(-0.0075 \mathrm{MHz} \mathrm{y}^{-1}\right)$ than that found using the regression method and including an F10.7 correction $\left(-0.0038 \mathrm{MHz} \mathrm{y}^{-1}\right)$. Table 1 shows that the higher $f \circ F 2$ trend is close to those calculated by Danilov (2002, 2003), Lastovicka et al. (2006, 2008b), Khaitov et al. (2012), and Ghabahou et al. (2013), whereas the weaker $f o F 2$ trend more closely matches that calculated by Mielich and Bremer (2013). Here, we can only note that twice removing the solar element of variations in foF2 (using the regression method and the 11-year running mean) provides a weaker $f o F 2$ trend than that obtained using only the 11-year smoothing.

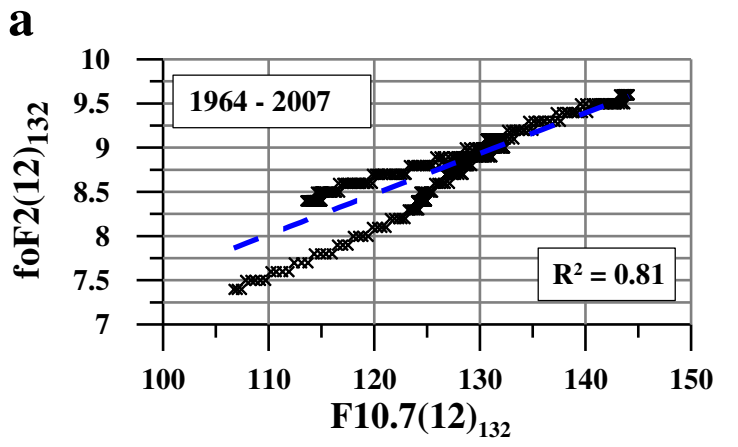

c



b

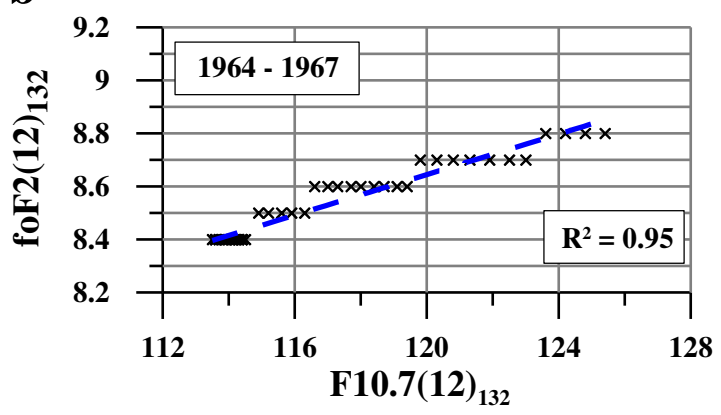

d

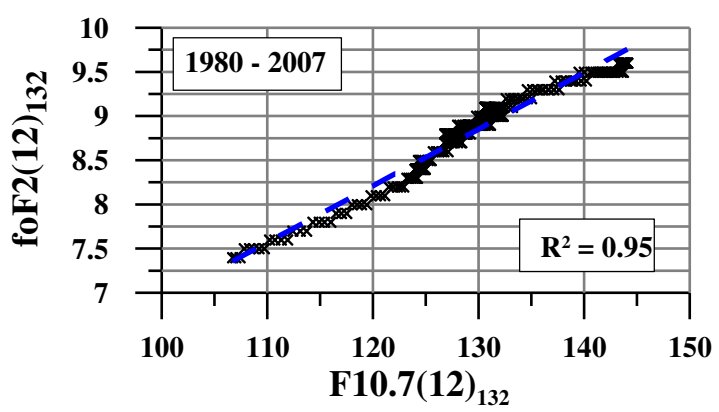

Figure 6 Plot of $f \circ F 2(12)_{132}$ versus $F 10.7(12)_{132}$ for periods: 1964-2007 (a), 1964-1967 (b), 1968-1979 (c), and 1980-2007 (d). 
Additionally, we calculated regressions for $f o F 2(12)_{132}$ as a function of $F 10.7(12)_{132}$ for different periods. Figure 6a shows that for the total interval (07.1963 to 08.2006), the correlation between the two variables forked into two distinct point groups assuming different relationships between $f o F 2(12)_{132}$ and $F 10.7(12)_{132}$ for different phases of the ca. 32-year cycle, a coefficient of determination $\left(R^{2}\right)$ of 0.81 was obtained. Figure $6 \mathrm{~b}, \mathrm{~d}$ shows linear relationships for the intervals showing a decrease (1964-1967; 19802007) and increase (1968-1979) in solar activity. It was found that $95 \%$ and $99 \%$ of the variations in $f o F 2(12)_{132}$ could be explained by linear relationships between $f \circ F 2$ (12) 132 and $F 10.7(12)_{132}$ for the decreasing and increasing intervals, respectively. The remaining variations in $f_{o F}$ (12) 132 are not explained by solar activity.

\section{Conclusions}

In this study, we derived a picture of long-term trends in foF2 for the ionosphere, using data from the mid-latitude ionosonde station at Alma-Ata $\left[43.25^{\circ} \mathrm{N}, 76.92^{\circ} \mathrm{E}\right]$ observed over about five solar cycles between 1957 and 2012. We showed that solar activity (as represented by F10.7) is significantly correlated with variations in $f \circ F 2$ and $A p$. In addition to the well-known 11-year solar cycle, the Sun also exhibits a cycle of about 30-32 years, which matches the period of trends observed in $A p$ and foF2. A negative trend is seen in long-term variations in $f \circ F 2$ between 1957 and 2012, and the magnitude of this trend was found to be -0.0038 and $-0.0075 \mathrm{MHz} \mathrm{y^{-1 }}$ for monthly absolute deviations $(\Delta f o F 2)$ and annual mean median $f o F 2$, respectively. This trend is considered too small to have practical meaning. It was found that $95 \%$ and $99 \%$ of the total variation in $f_{0} F 2(12)_{132}$ could be explained by linear relationships between $f_{0} F 2(12)_{132}$ and $F 10.7(12)_{132}$ for periods increasing and decreasing solar activity, respectively. The remaining variations in $f o F 2(12)_{132}$ cannot be explained by solar activity.

\section{Competing interests}

The authors declare that they have no competing interests.

\section{Authors' contributions}

All authors have been involved in data interpretation, drafting the manuscript, and revising it critically. All authors read and approved the final manuscript.

\section{Acknowledgements}

We thank two anonymous reviewers for their careful reviews that helped significantly improve this manuscript. This research was supported by the Kazakhstan National Center for Space Research and Technology and funded through the Institute of Ionosphere (Research Project 0112PK00290).

Received: 31 March 2014 Accepted: 3 September 2014

Published: 17 October 2014

\section{References}

Chen Y, Liu L, Le H, Wan W (2014) How does ionospheric TEC vary if solar EUV irradiance continuously decreases? Earth Planets Space 66:52. http://www. earth-planets-space.com/content/66/1/52
Clilverd MA, Clark TDG, Clarke E, Rishbeth H (1998) Increased magnetic storm activity from 1868 to 1995. J Atmos Solar-Terr Phys 60:1047-1056

Clúa de Gonzalez AL, Gonzalez WD, Dutra SLG, Tsurutani BT (1993) Periodic variation in the geomagnetic activity: a study based on the Ap index. J Geophys Res 98:9215

Danilov AD (2002) The method of determination of the long-term trends in the F2 region independent of geomagnetic activity. Ann Geophys 20:511-521. doi:10.5194/angeo-20-511-2002

Danilov AD (2003) Long-term trends of foF2 independent of geomagnetic activity. Ann Geophys 21:1167-1176. doi:10.5194/angeo-21-1167-2003

Danilov AD (2012) Changes in the upper atmosphere and ionosphere over the last decades (Review, in Russian). In: http://vestnik.geospace.ru/issues/iss1/ article2.pdf

Danilov AD (2013) Trends in the F2-layer parameters at the end of the 1990s and the beginning of the 2000s. J Geophys Res 118:3712-3718. doi:10.1002/ jgra. 50352

Echer E, Rigozo NR, Nordemann DJ R, Vieira LEA (2004) Prediction of solar activity on the basis of spectral characteristics of sunspot number. Ann Geophys 22:2239-2243. SRef-ID: 1432-0576/ag/2004-22-2239

Ghabahou DA, Ehias G, Ouattara F (2013) Long-term trend of foF2 at a West African equatorial station. J Geophys Res 118:3909-3913. doi:10.1002/jgra.50381

Khaitov R, Kolesnik S, Sarychev V (2012) Seasonal, diurnal variations critical frequency in the F2-layer over middle latitudes. In: Paper presented at the 7th IAGA/ICMA/CAWSES Workshop on Long-Term Changes and Trends in the Atmosphere, Buenos Aires, 11-14 September

Lastovicka J (2009) Global pattern of trends in the upper atmosphere and ionosphere: recent progress. J Atmos Solar-Terr Phys 71:1514-1528

Lastovicka J, Mikhailov AV, Ulich T, Bremer J, Elias AG, Ortis de Adler N, Jara V, Abarca del Rio R, Foppiano AP, Ovalle E, Danilov AD (2006) Long-term trends in foF2: a comparison of various methods. J Atmos Solar-Terr Phys 68:1854-1870

Lastovicka J, Akmaev RA, Beig G, Bremer J, Emmert JT, Jacobi C, Jarvis MJ, Nedoluha G, Portnyagin Yl, Ulich T (2008a) Emerging pattern of global change in the upper atmosphere and ionosphere. Ann Geophys 26:1255-1268

Lastovicka J, Yue X, Wan W (2008b) Long-term trends in foF2: their estimating and origin. Ann Geophys 26:593-598

Mielich J, Bremer J (2013) Long-term trends in the ionospheric F2 region with different solar activity indices. Ann Geophys 31:291-303

Mikhailov AV (2006) lonospheric long-term trends: can the geomagnetic control and the greenhouse hypotheses be reconciled? Ann Geophys 24:2533-2541

Raspopov OM, Shumilov OI, Kasatkina EA, Turunen E, Lindholm M (2000) 35-year climatic Bruckner cycle-solar control of climate variability. In: Paper presented at the 1st Solar and space weather euro conference. "The Solar Cycle and Terrestrial Climate", Santa Cruza de Tenerife, Tenerife, Spain, p 2000

Rishbeth H (1990) A greenhouse effect in the ionosphere? Planet Space Sci 38:945-948

Rishbeth H, Roble RG (1992) Cooling of the upper atmosphere by enhanced greenhouse gases - modelling of the thermospheric and ionospheric effects. Planet Space Sci 40:1011-1026

Yamazaki Y, Yumoto K (2012) Long-term behavior of annual and semi-annual $S_{q}$ variations. Earth Planets Space 64:417-423

Yue X, Wan W, Liu L, Ning B, Zhao B (2006) Applying artificial neural network to derive long-term foF2 trends in the Asia/Pacific sector from ionosonde observations. J Geophys Res 111:A10303. doi:10.1029/2005JA011577

doi:10.1186/1880-5981-66-125

Cite this article as: Gordiyenko et al:: A long-term trend in the F2-layer critical frequency as observed at Alma-Ata ionosonde station. Earth, Planets and Space 2014 66:125. 